\title{
Colômbia: Defesa Constitucional de uma democracia ameaçada*
}

\section{Augusto Hernández Becerra}

\section{Resumo}

As democracias estão seriamente ameaçadas pela intrusão do crime organizado na política. $\bigcirc$ artigo descreve algumas estratégias de ordem constitucional e legal empregadas na Colômbia para que o Estado possa defender as instituições democráticas com tanta energia quanto necessária para neutralizar a violência e o dinheiro que utilizam seus inimigos para as atacar. Entre essas estratégias se arrolam a "cadeira vazia" nas corporações públicas, a supressão do foro como sinônimo de imunidade ou impunidade, a ação de perda de mandato, a extinção judicial do domínio sobre bens ilicitamente adquiridos. Palavras-chave: Democracia; Crime Organizado; Reforma Política; Responsabilidade de Partidos Políticos; Estado de Direito.

\begin{abstract}
Democracies are seriously threatened by the intrusion of organized crime in politics. The article describes some strategies of constitutional and legal order used in Colombia for the State to defend democratic institutions with as much energy as it deems necessary to neutralize violence and money their enemies use to attack them. Among these strategies are the "empty chair" in public corporations, suppression of congressmen immunity as a synonym for immunity or impunity, trial loss of investiture, the judicial extinction of the domain over illicitly acquired goods.
\end{abstract}

Keywords: Democracy; Organized Crime; Political Reform; Responsibility of Political Parties; Rule of Law.

Artigo recebido em 26 de novembro de 20।4; aceito para publicação em 12 de janeiro de 2015.

\section{Sobre o autor}

Professor Emérito da Universidad Externado de Colombia e ex-Conselheiro de Estado.

* Artigo traduzido do original em espanhol "Colombia: defensa constitucional de una democracia amenazada”. Tradução realizada por Jane Guedes Sobreira - licenciada em Letras Português-Espanhol pela Pontifícia Universidade Católica do Paraná - e por Renan Guedes Sobreira - bacharel em Direito pela Universidade Federal do Paraná e pós-graduado em Direito Parlamentar pela Universidad Nacional Autónoma de México. 


\section{Introdução}

As democracias estão ameaçadas quando enfrentam perigos extremos que poderiam desequilibrá-las. Assim ocorreu com o desafio dos totalitarismos que levaram à Segunda Guerra Mundial e à Guerra Fria. Os golpes militares tornaram impossível, reiteradamente, a democracia em muitos países da América Latina durante o século $\mathrm{XX}$. Atualmente, as ameaças vêm do crime organizado que se nutre do narcotráfico. Colômbia, México e América Central entram na categoria de democracias ameaçadas por este motivo.

Neste artigo se expõem algumas estratégias de ordem constitucional e legal a que recorreu a Colômbia para dotar o Estado de instrumento que o permitam assumir a defesa das instituições democráticas com tanta energia quanto necessário para neutralizar a violência e o dinheiro que utilizam seus inimigos para as atacar.

A principal estratégia consistiu em retirar os criminosos dos espaços políticos que lograram conquistar durante anos de inconsciência, indolência, indiferença, tolerância e cumplicidade nacionais. Espaços políticos devem ser entendidos em referência às eleições e, em especial, aos congressistas.

A exposição se desenvolve em duas partes. A primeira consiste em uma reflexão geral sobre as ameaças que hoje enfrenta a democracia. A segunda descreve alguns instrumentos constitucionais para fazer efetiva a responsabilidade política e procurar maior sujeição dos dirigentes políticos ao Estado de Direito e ao controle dos juízes.

\section{O que está acontecendo com a democracia?}

O que acontece com a democracia em meu país? Essa pergunta, cada mais frequente nos lábios dos cidadãos preocupados e na mente de dirigentes e acadêmicos, envolve perplexidade e impotência evidenciando as limitadas capacidades da ciência social para elaborar explicações convincentes e oferecer soluções praticáveis. Será que erramos o caminho, que a crise é companheira inseparável da política, que a democracia é um processo que requer tempos de amadurecimento ainda não finalizados, que a economia opera influência maior do que supomos ou que devemos buscar chaves desconhecidas na diversidade das tradições e culturas? Ante a falta de respostas idôneas a tais perguntas, o ceticismo e o desencanta se instalaram 
no imaginário coletivo e ameaçam, pela abstenção eleitoral e pela falta de credibilidade cidadã, a viabilidade do ideal democrático.

Nas democracias ameaçadas, a sociedade se indigna e se alarma ante o espetáculo de algumas instituições que não logram acomodação aos padrões mínimos do Estado de Direito e da democracia representativa e que, pelo contrário, retrocedem ante ao impulso de forças insidiosas que conspiram para obter benefícios particulares com absoluta desprezo pelo interesse geral.

Entre todos, ou ao menos entre muitos, atuando como sociedade, queremos construir um Estado ao qual confiamos a realização de um projeto político fundado no bem comum, entendendo este como a primazia do interesse geral sobre os interesses particulares e a proteção e garantia da justiça, da liberdade, da democracia, da equidade e da dignidade humana. Nobres propósitos que dependem da saúde democrática das instituições.

Esforços e sacrifícios consideráveis se realizaram na América Latina durante anos para fortalecer e proteger as instituições democráticas. Reformaram-se as Constituições e as leis em procura de partidos políticos modernos, de um sistema eleitoral transparente, neutro e confiável, de um regime equitativo de financiamento estatal de campanhas e de partidos, de uma estrita regulamentação e vigilância da atividade política. Tentou-se tudo quanto dita a cartilha elaborada por especialistas na engenharia eleitoral no mundo. Bem se sabe que é importante melhorar o funcionamento dos órgãos legislativos, promover a democracia participativa, descentralizar a administração no território, contar com juízes independentes e probos, profissionalizar a polícia com profissionais comprometidos com os direitos humanos.

Questões estruturais impõem dificuldades que parecem transpor as capacidade da institucionalidade democrática idealmente construída pela cultura ocidental moderna, em especial a pobreza da maioria da população, com seu séquito de carências de tudo quanto é essencial em saúde e educação. São muito altos os índices de desigualdade, marginalidade e desemprego. Também é muito aguda em nossos países a discriminação por motivos raciais e socioeconômicos, a marginalidade e a exclusão. São problemas que requerem políticas patrocinadas de longo prazo e ação política perseverante.

A democracia enfrenta também formidáveis desafios de conjuntura. O cenário da política, hoje, não é somente de uma competição 
eleitoral entre partidos políticos pela conquista do governo, na qual atuam eleitores e candidatos. Converteu-se em uma desigual contenda entre atores políticos legítimos, de um lado, e, do outro, pessoas ou organizações decidias a transgredir todas as regras do ordenamento jurídico e da ética para capturar não só o governo, mas o Estado em sua totalidade.

O comércio de drogas é, atualmente, a expressão mais vigorosa do crime organizado e do delito multinacional. Busca e encontra sócios e colaboradores, voluntários ou forçados, na economia formal e no mundo político. Os chefes do narcotráfico, embevecidos pela fundada sensação de que não existe poder que os detenha, atuaram, inclusive, diretamente na política. Entretanto, a alta exposição à mídia e à opinião pública lhes demonstrou que eram vulneráveis. Optaram, então, por recuar a uma posição mais discreta, infiltrar-se na economia formal por meio de testas de ferro e cooptar as classes dirigentes do setor privado e do mundo político para resguardar seus negócios ilícitos, neutralizar as ações da polícia e da justiça, facilitar a lavagem de dinheiro proveniente do delito e amparar suas propriedades e negócios legalizados.

O poder do dinheiro e da força bruta participa ativamente, como nunca antes, do jogo da política. As eleições se encareceram irracionalmente. Não só se compram votos, como também eleições inteiras e toda prefeitura, governadoria ou vaga eleitoral tem um preço que os senhores da droga ou seus intermediários, auxiliadores, sócios, colaboradores, estão dispostos a pagar. Em numerosos casos se instauraram autênticas narco-democracias municipais e regionais, sendo que o problema já começa a se converter em verdadeira calamidade nacional para vários países.

Assim, configuraram-se formas extremas de corrupção que, por sua intensidade e extensão, ameaçam, como nunca antes, desequilibrar a ordem constitucional. A verdade é que outras formas de corrupção, com as quais estamos familiarizados, endêmicas e de baixa intensidade, não são tão perigosas como as que aqui se analisam.

As eleições, sempre necessárias para separar o governo do povo, têm agora uma função mais crucial, pois se converteram no cenário no qual se decide a sobrevivência das instituições democráticas. Este é o novo enfoque, também, das funções e responsabilidades dos partidos políticos e do regime dos congressistas, das corporações de representação popular em geral e de todos os eleitos. 
Este é o panorama da crise que serviu para ensaiar na Colômbia, há umas duas décadas, com titubeios iniciais, mas com constância, estratégias urgentes para defender a democracia ameaçada. Foi necessário instrumentalizá-las a partir da Constituição, pois se necessitava revisar instituições tradicionais, como o foro parlamentar, e criar outras inteiramente novas e mesmo experimentais, como a perda de mandato dos congressistas, a atribuição de novos poderes de investigação e sanção às autoridades, a criação de novas modalidades delitivas e procedimentos judiciais especiais, como a extinção do domínio de bens adquiridos por meios ilícitos.

Não em vão estamos vivendo uma era de reformas políticas incessantes. Desde 1991, na Colômbia, já se efetuaram quatro dessas. Para ajustar uma ou outra vez as normas constitucionais sobre partidos políticos, campanhas eleitorais, financiamento da atividade política, sistema eleitoral, direito de sufrágio, organização eleitoral, Congresso da República.

Em tempos de crise, o Estado concentra seu poder e reforça suas atribuições como autoridade. A onda reformadora da última década para estabelecer a reeleição presidencial na América Latina faz parte dessa panóplia de reformas centralizadoras de urgência. Revisam-se os códigos para introduzir novos tipos penais, incrementar as penas e agilizar os procedimentos judiciais. Logo após a devolução de competências e recursos financeiros do centro político nacional à periferia, política que caracterizou uma era de confiança e otimismo, começamos a reviver um período de recentralização, no qual o nível nacional recolhe o poder que havia distribuído às localidades e regiões para enfrentar melhor a crise. Parece evidente que a descentralização territorial não se concilia com as grandes crises do Estado.

Colômbia, país de profundas contradições, devido à sua singular circunstância de haver sido o principal produtor e exportador de cocaína do mundo, e de haver sido um país com uma excepcional trajetória de continuidade democrática (desde 1832 até o presente unicamente teve governos à margem da ordem constitucional durante oito anos), foi o cenário de uma luta feroz entre democratas e inimigos das instituições durante as últimas décadas. Por tais motivos que se converteu num laboratório de constante busca e experimentação no campo das reformas jurídicas para defender as instituições. 


\section{Responsabilidade dos dirigentes políticos. Sujeição à lei e aos controles judiciais}

A instituição estratégica para amainar esta luta pela defesa das instituições democráticas foi o Congresso da República e o instrumento para operacionalizar a estratégia de defesa, a justiça.

A Constituição de 1991 submeteu os congressistas, e por extensão todos os membros das corporações públicas, a um regime estrito de incapacidades, incompatibilidades, proibições e conflito de interesses. Desde 1991 se viu com claridade que, ante as incursões do crime organizado na política, era de interesse nacional sujeitar aos dirigentes políticos a exigentes regras de ordem ética e a jurisdição ordinária em direito penal. Desde então, o foro dos congressistas se reduz ao privilégio de ser investigado e julgado na esfera criminal pela Suprema Corte de Justiça sem sujeição a procedimentos prévios de qualquer natureza. $\mathrm{O}$ nepotismo, a acumulação de cargos eletivos, o tráfico de influências ficaram proibidos, sob ameaça de perda de mandato.

A perda de mandato é um procedimento especial, de natureza ético disciplinar, que se desenvolve contra os congressistas perante o Conselho de Estado por qualquer violação ao regime de capacidades, incompatibilidades ou conflitos de interesse, por iniciativa das mesas diretoras das câmaras ou de qualquer cidadão. O Conselho de Estado atua em única instância no prazo de vinte dias, logo após ter produzido provas e haver escutado os argumentos da defesa. O procedimento de perda de mandato para deputados, vereadores e prefeitos se dá perante os tribunais administrativos, também em única instância. Quem perde seu mandato não pode voltar a ser eleito para o posto do qual foi retirado.

No ano de 2009, reformou-se a Constituição (Ato Legislativo ${ }^{\circ}$ 01 de 2009, desenvolvido pela Lei $n^{\circ} 1.475 / 11$ ) com o objetivo de fortalecer os partidos e movimentos políticos mediante uma ambiciosa trama de regras sobre organização, funcionamento, proibições, sanções, controles e responsabilidades.

Impôs-se às organizações políticas o dever de adotar uma organização democrática e a sujeição aos princípio da transparência, objetividade, moralidade, equidade de gênero e publicidade de seus programas políticos, sujeição ao regime de bancadas, à prática de consultas populares e vinculação aos resultados dessas. 
O mais particular dessa reforma consiste na adoção de medidas rigorosas e sem precedentes para proteger a política da presença ou influência do crime organizado. Para dar eficiência às novas medidas, selecionaram-se aqueles delitos em que habitualmente o crime organizado incorre para participar da vida política e onde a linguagem seja o uso ilimitado de violência e dinheiro. Trata-se de delitos relacionados com grupos armados ilegais, narcotráfico, violação dos mecanismos de participação democrática e de lesa humanidade.

Nesses moldes, os partidos e movimentos políticos responderão por toda violação ou contravenção às normas que regem sua organização, funcionamento ou financiamento, assim como também por inscrever candidatos que forem condenados na Colômbia ou no exterior por delitos relacionados com grupos armados ilegais, narcotráfico, violação dos mecanismos de participação democrática ou lesa humanidade. Em nenhum caso poderão ser inscritos como candidatos, nem eleitos, que tenham sido condenados por esses delitos nem quem seja responsável por condenação do Estado a uma reparação patrimonial.

A reforma de 2009 instituiu o que se veio a conhecer como a "cadeira vazia", conceito que se aplica ao Congresso da República, às assembleias estaduais, aos conselhos municipais e às juntas administradores locais. Essa nova figura consiste na vedação de substituição de um membro de uma empresa pública de eleição popular a partir do momento em que seja proferida ordem de prisão, dentro de um processo penal atrelado a delitos relacionados com ao pertencimento, promoção ou financiamento de grupos armados ilegais, do narcotráfico ou de delitos de lesa humanidade.

Adicionalmente, a sentença condenatória produzirá como efeito a perda definitiva da vaga para o partido. Ademais, a renúncia de um membro de uma empresa pública de eleição popular, quando acusado formalmente por delitos cometidos na Colômbia ou no exterior, relacionados com pertencimento, promoção ou financiamento de grupos armados ilegais, narcotráfico ou delitos contra os mecanismos de participação democrática ou de lesa humanidade, gerará a perda de sua qualidade de congressista, deputado, vereador ou prefeito e não poderá ser substituído.

A Lei $\mathrm{n}^{\circ} 1.475 / 11$ submete a um estrito regime de responsabilidade as instituições partidárias e as pessoas que as dirigem a partir de uma detalhada tipificação de faltas, a delimitação de sanções 
correspondentes e a designação precisa de competências sancionadas pelo Conselho Nacional Eleitoral e a regulamentação de um procedimento punitivo especial.

De acordo com esta lei, são responsáveis os partidos e movimentos políticos por toda contravenção ou violação das normas que regem sua organização, funcionamento ou financiamento, assim como de maneira pessoal os seus diretores quando incorram em faltas anunciadas no art. $8^{\circ}$ e enumeradas pelo art. 10 desse estatuto, o que se verá a seguir.

\section{Faltas}

De acordo com o art. 10 da Lei $n^{\circ} 1.475 / 11$, constituem faltas sancionáveis as seguintes ações ou omissões imputáveis aos diretores dos partidos e movimentos políticos: descumprir os deveres de aplicar as normas que regulam a organização, funcionamento e/ou financiamento dos partidos políticos e movimentos políticos; permitir o financiamento da organização e/ou das campanhas eleitorais com fontes de financiamento proibidas; violar ou permitir que se violem os tetos de entradas e gastos nas campanhas eleitorais; inscrever candidatos a cargos ou empresas de eleição popular que não reúnam os requisitos ou qualidades, que se incorram nas hipóteses de incapacidade ou incompatibilidade ou que tenham sido condenados ou venham a sê-lo durante o período para o qual foram eleitos, por delitos cometidos em relação a vinculação a grupos armados ilegais, atividades do narcotráfico, aos mecanismos de participação democrática ou a lesa humanidade; utilizar ou permitir o uso da violência para o exercício da participação política e eleitoral; cometer delitos contra mecanismos de participação democrática, contra a administração pública, contra a existência e segurança do Estado, contra o regime constitucional e legal, de lesa humanidade ou relacionados com atividades de grupos armados ilegais ou de narcotráfico; cometer delitos contra a administração pública, atos de corrupção; mostrar conivência com esses e/ou tendo conhecimento de tais situações, não iniciar os processos correspondentes ou não realizar as denúncias do caso.

A lei tipifica com especial rigor aquelas faltas que denotam conspiração entre o crime organizado e a política, fenômeno que em esta época se tornou a ameaça mais grave contra as instituições 
democráticas. A lei considera como falta muito grave que os diretores de partidos e movimentos permitam o ingresso de recursos proibidos. Igualmente os faz responsáveis pela simples inscrição de candidatos que tenham sido condenados ou cheguem a sê-lo durante o período para o qual foram eleitos por delitos cometidos relacionados com a vinculação a grupos armados ilegais, atividades do narcotráfico ou crimes contra os mecanismos de participação democrática e aqueles de lesa humanidade.

A lei, inclusive, torna responsáveis os partidos ou movimentos políticos por aprovar a candidatos que não sejam eleitos, se no passado foram condenados por delitos relacionados à vinculação a grupos armados ilegais e atividades do narcotráfico (art. $10^{\circ}$, parágrafo único) durante o período ao qual aspiraram a cargos eletivos.

\section{Sanções}

Os diretores de partidos e movimentos políticos que incorram em qualquer das faltas descritas no art. 10, estarão sujeitos a sanções (art. 11) que podem consistir em advertência escrita e pública, suspensão do cargo diretivo por até três meses, destituição, expulsão do partido ou movimento e outras sanções estabelecidas pelos estatutos dos partidos ou movimentos.

Os órgãos de controle dos partidos e movimentos políticos estão encarregados de impor as sanções de acordo com a gravidade da falta, mediante procedimento previsto em seus estatutos e com respeito ao devido processo legal. As sanções que impõem as organizações políticas podem ser impugnadas perante o Conselho Nacional Eleitoral.

Doutra parte, os partidos e movimentos políticos com personalidade jurídica pode ser sancionados quando as faltas sejam imputáveis a seus diretores, a seus candidatos a cargos ou empresas de eleição popular ou, em geral, quando seus diretores não adotem as medidas tendentes a evitar a realização de tais ações e omissões ou quando não iniciem os procedimentos internos de investigação e sanção. Essas sanções podem consistir em suspensão ou privação do financiamento estatal e dos espaços em meios de comunicação social, suspensão de sua personalidade jurídica, suspensão do direito de inscrever candidatos ou listas, cancelação de sua personalidade jurídica e dissolução da organização política. 
Quando lavradas condenações, seja na Colômbia ou no exterior, por delitos relacionados com a vinculação a grupos armados ilegais e atividades do narcotráfico ou por delitos contra os mecanismos de participação democrática ou de lesa humanidade, o partido que inscreveu o condenado não poderá apresentar candidatos para a eleição seguinte na mesma circunscrição.

Os movimentos políticos perderão o reconhecimento de sua personalidade jurídica quando, ao subtrair os votos obtidos pelos congressistas condenados por delitos a que se refere o numeral $5^{\circ}$ do art. 10, não se atingir o mínimo eleitoral. Nesses casos, ordenase adicionalmente a devolução do financiamento estatal da campanha em uma quantidade equivalente ao número de votos obtidos pelo congressista ou congressistas condenados. A devolução dos recursos também se aplica quando se trata de candidatos a cargos uninominais. No casos de lista fechada, a devolução se dá de forma proporcional ao número de candidatos eleitos.

A lei prevê a adoção de medidas adicionais relacionadas com o financiamento estatal, o direito de utilizar os meios de comunicação social, a personalidade jurídica e mesmo a dissolução da organização. Em determinados casos, as sanções poderão ser impostas com efeitos limitados à circunscrição na qual se cometeram as faltas sancionáveis.

\section{Procedimento sancionatório}

O Conselho Nacional Eleitoral, autoridade superior da Organização Eleitoral, tem competência para regular, inspecionar, vigiar e controlar "toda a atividade eleitoral dos partidos e movimentos políticos, dos grupos significativos de cidadãos, de seus representantes legais, diretores e candidatos", e garantir o cumprimento dos princípios e deveres a que eles correspondem (art. 265 da Constituição Colombiana), competindo-lhe ainda impor sanções cabíveis nos termos da lei (art. 13 da Lei n ${ }^{\circ}$ 1.475/11).

O procedimento punitivo aparece regulado no art. 13 da Lei $\mathrm{n}^{\circ} 1.475 / 11 \mathrm{e}$, naturalmente, deverá satisfazer todas as exigências constitucionais do devido processo administrativo. A resolução mediante a qual se formulam as acusações deverá indicar com claridade e precisão as faltas atribuídas, os fatos objetos de investigação, as provas de que se dispõe, as disposições infringidas e as sanções aplicáveis. Se o Conselho Nacional Eleitoral não dispuser 
de elementos judiciais suficientes para formular acusações, realizará previamente investigação preliminar, cujo início será informado à respectiva organização política.

Uma vez notificada pessoalmente da resolução de abertura da investigação, o representante legal do partido ou movimento vinculado à investigação e as pessoas implicadas nos fatos objeto de investigação poderão responder às acusações, juntar provas e solicitar as arguições que considere pertinentes. Uma vez encerrada a fase probatória, as pessoas vinculadas serão informadas para que apresentem suas manifestações finais. Nos dois meses seguintes, a empresa deverá emitir resolução definitiva.

Os aspectos do procedimento previstos na Lei $\mathrm{n}^{\circ} 1.475 / 11$ se regulam, no que pertinente, pelo Código de Processo Administrativo e de Contencioso Administrativo, art. 47 a 52 da Lei n ${ }^{\circ}$ 1.437/11.

A decisão adotada pelo Conselho Nacional Eleitoral é um ato administrativo que poderá ser questionando perante o Conselho de Estado. $\mathrm{O}$ art. 13, numeral 7 da Lei $\mathrm{n}^{\circ} 1.475 / 11$, prescreve que, quando a sanção for de dissolução, cancelação ou suspensão da personalidade jurídica, a demanda contenciosa administrativa contra o ato tramitará de forma preferencial e será registrada como prioridade, sendo que qualquer assunto diverso, exceto habeas corpus e ações de tutela, será adiado.

O art. 14 da Lei n ${ }^{\circ}$ 1.475/11 regula a dissolução, liquidação, fusão e cisão de partidos e movimentos políticos. Inicialmente, dispõe que esta matéria se regerá pelo disposto na lei e/ou nos estatutos e que, se a medida for adotada por decisão administrativa sancionatória do Conselho Nacional Eleitoral, não haverá recurso cabível.

Uma vez notificada a decisão que decretou a dissolução, cessará de imediato toda atividade do partido ou movimento político. Os atos executados posteriormente à execução da decisão se reputarão inexistentes e se considerará fraudulenta a criação de novo partido ou movimento político ou a utilização de outro que continue ou suceda a atividade da organização dissolvida (art. 15 da Lei n ${ }^{\circ}$ 1.475/11).

\section{Reflexão final}

É lícito ao Estado de Direito ajuntar forças para defender as instituições contra a força empregada pelos violentos. Isso não significa, por óbvio, suspender nem derrogar as liberdades e direitos. 
Pelo contrário, trata-se de defende-los com plena garantia dos princípios e regras constitucionais e dos procedimentos próprios do devido processo legal. Porém, deve-se utilizar mecanismos mais eficazes, criar meios de controle mais especializados e independentes da instância política e aplicar procedimentos mais ágeis e eficientes. Para este propósito, sempre é possível revisar instituições ultrapassadas e ajustar formalidades de antigas tradições para garantir os resultados de uma ação contundente de proteção e defesa da Constituição.

$\mathrm{Na}$ Colômbia, conseguiram-se resultados notáveis graças à ação de uma justiça profissional, que sou guardar distância em relação à instância política. Quem sabe por tal razão, porque é demasiadamente independente, em várias oportunidades, os dirigentes políticos quiseram reformar o Poder Judiciário. Está claro, assim, que se a liberdade dos juízes chegar a curvar-se diante dos interesses dos partidos ou de grupos, cairá a última trincheira em defesa da democracia.

\section{Referências}

A.A.V.V. (2013). Derecho electoral de América Latina. Bogotá: Consejo de Estado, Sala de Consulta y Servicio Civil.

García de Enterría, E. (2004). Democracia, ley e inmunidades del poder. Lima: Palestra Editores.

Hernández Becerra, A. (2004). Regulación jurídica de los partidos políticos en Colombia. In: Análisis comparado de los partidos políticos en América Latina: normativa y práctica. San José de Costa Rica: International Idea (Institute for Democracy and Electoral Assistance).

Hernández Becerra, A. (2011). Actividad política y responsabilidad en Colombia. In: Estudios de Derecho Electoral - Memorias del Congreso Iberoamericano de Derecho Electoral. Ciudad de México: Universidad Nacional Autónoma de México.

Hernández Becerra, A. (2012). Principio democrático y partidos políticos en Colombia. In: ¿Hacia una ley de partidos políticos? Experiencias latinoamericanas y prospectiva para México. Ciudad de México: UNAM, IDEA International, Instituto Belisario Domínguez de Estudios Legislativos del Senado de la República. Vanegas Gil, P. P. (2007). Estudios de Derecho Electoral. Bogotá: Universidad Externado de Colombia. 